\title{
STUDY OF INSULIN TO GLUCAGON RATIO AND ITS CORRELATION WITH THYROID HORMONES IN STREPTOZOTOCIN INDUCED TYPE 2 DIABETES.
}

\begin{abstract}
1. MBBS, M.Phil
Assistant Professor of Physiology

Rawal Institute of health sciences, Islamabad.

2. MBBS, M.Phil

Assistant Professor of Physiology Frontier Medical and Dental College, Abbottabad.

3. MBBS, M.Phil

Assistant Professor of Physiology

Wateen Medical and Dental College, Rawalpindi.

4. MBBS, M.Phil

Assistant Professor of Physiology

Fazaia Medical College, Islamabad.

5. MBBS, FCPS

Assistant Professor of Physiology

Alrazi Medical College, Peshawar.

6. MBBS, M.Phil

Assistant Professor of Physiology,

Rawal Institute of health sciences, Islamabad.
\end{abstract}

Correspondence Address:

Dr. Sidra Arshad

Assistant Professor of Physiology

House no 22, Main Boulevard

Doctor's Cooperative Housing Society, Islamabad.

sidraarshad83@hotmail.com

Article received on:

02/08/2019

Accepted for publication:

$08 / 11 / 2019$
Sidra Arshad ${ }^{1}$, Muhammad Sajid Mehmood², Lubna Siddique ${ }^{3}$, Shahida Parveen ${ }^{4}$, Amina Rasul $^{5}$, Hira Ayaz ${ }^{6}$

ABSTRACT... Objectives: To determine correlation between insulin to glucagon ratio and thyroid hormones levels in the two groups. Study Design: Randomized Control Trial. Settings: Physiology Department of Army Medical College, Rawalpindi and National Institute of Health $(\mathrm{NIH})$, Islamabad. Period: 6 months (from $1^{\text {st }}$ January 2017 to $30^{\text {th }}$ June 2017 ). Material \& Methods: A sample of sixty apparently healthy Sprague Dawley rats was selected randomly. It was divided into two groups i.e control and diabetic. It was ensured that all the rats were euglycemic and euthyroid at the start of the study by investigating serum thyroid stimulating hormone (TSH) and serum glucose levels. The control group was given with normal pellet diet whereas, STZ induced rats were fed on high fat diet while. The control group were injected with saline injection intraperitoneally after 2 weeks, while low dose of streptozotocin was injected to diabetic rats. The induction of diabetes mellitus was affirmed by checking plasma glucose levels and homeostatic model for insulin resistance (HOMA-IR). The specific diet was continued for another five weeks in both the groups. The terminal sample was investigated for plasma glucose using glucose oxidase method and serum insulin, TSH, T3 and T4 levels using ELISA technique. Results: The serum insulin and glucose levels were elevated in diabetic group as compared to the control group. HOMA-IR was also raised significantly in the diabetic group. The serum TSH and T4 levels were considerably higher $(p<0.001)$ while serum T3 was comparable in both the groups. There was no correlation between Insulin to Glucagon Ratio and TSH, T3 and T4 both in control and diabetic groups. Conclusion: Serum glucose, serum insulin and HOMA-IR were raised in the diabetic group. Serum TSH and T4 levels were also increased while no change in serum T3 levels. IGR and thyroid hormones were not correlated in either group.

Key words:

HOMA-IR, Insulin to Glucagon Ratio, Insulin Resistance, Thyroid Hormones, Thyroid Stimulating Hormone (TSH), Type 2 Diabetes Mellitus.

Article Citation: Arshad S, Mehmood MS, Siddique L, Parveen S, Rasul A, Ayaz H. Study of insulin to glucagon ratio and its correlation with thyroid hormones in streptozotocin induced type 2 diabetes. Professional Med J 2020; 27(7):1396-1400. DOI: 10.29309/TPMJ/2020.27.07.4003

\section{INTRODUCTION}

Insulin and glucagon are two hormones which have opposite effects but they work towards in maintaining a normal energy balance. Pancreas regulate the production of glucose, synthesis of proteins and triacylglycerol deposition by regulating the relative concentrations of insulin and glucagon produced by the alpha and beta cells. ${ }^{1}$ Glucagon has a catabolic effect, whereas the physiological effect of insulin is anabolic in nature. Insulin to glucagon ratio (IGR) is a suitable parameter to assess the collective effects of the two hormones. IGR less than normal exerts an overall catabolic effect on carbohydrates by increasing its glycogenolysis and gluconeogenesis, and fatty tissue is broken down into glycerol and free fatty acids. IGR on a higher side exerts anabolic effect by promoting the synthesis of proteins, stopping the synthesis of glucose, and decreases the release of free fatty acid. ${ }^{2}$

In type 2 diabetes mellitus, the disturbance in the endocrine activity of the pancreas is not limited to insulin, since an associated increase in fasting plasma glucagon and impaired suppression after the ingestion of an oral glucose load are often observed. It leads to altered IGR in patients with type 2 diabetes. ${ }^{3}$

The association between thyroid abnormalities 
and diabetes mellitus has been assessed in a number of studies. The literature reveals that multiple endocrinal dysfunctions lead to stimulation of a series of reactions which are actually antihomeostatic in nature. It is critical to investigate thyroid function in T2DM patients, and this practice should be incorporated in clinical settings to promote further understanding of relation between thyroid abnormalities and T2DM. ${ }^{4}$ Keeping in view the above literature, the present study is aimed to find out correlation between IGR and thyroid profile in non-diabetics and type 2 diabetics.

\section{OBJECTIVES}

To compare thyroid hormones and insulin to glucagon ratio in type 2 diabetes.

To determine correlation between insulin to glucagon ratio and thyroid hormones levels in the two groups.

\section{MATERIAL AND METHODS}

A total of 60 rats weighing $250 \pm 50$ grams were selected for the study. Sprague dawley rats were selected for the study. First of all diabetic rats were excluded by measuring glucose levels by using glucometer (On Call Plus). Serum TSH levels were measured by using ELISA (Cusabio) kit to exclude rats with thyroid disease.

Two groups (control and diabetic), were formed with thirty rats in each group. Rats in the control group were provided with normal pellet diet and rats of diabetic group were fed on diet high in fat content. Water was given to both the groups ad libitum. After a period of two weeks, an injection of streptozotocin (STZ), 35mg/kg was administered intraperitoneally to diabetic group and at the same time normal saline injections were given to the control group. Homeostatic model assessment for insulin resistance (HOMA-IR) was worked out after 1 week of STZ administration, to check the induction of type 2 diabetes. This was done by taking blood sample from rat tail vein. In this way, a rat model closely resembling human T2DM was generated. Subsequently, the same diet was continued for another 5 weeks. ${ }^{5}$
Intracardiac sampling was done at the completion of five weeks ( 8 weeks in total) by placing the rats one at a time, in a glass jar having ether soaked cotton. Blood sample was drawn after the rats were completely unconscious. ${ }^{6}$ The samples were centrifuged for $15 \mathrm{~min}$ at a frequency of $4000 \mathrm{rpm}$. The plasma and serum was stored in the polypropylene tubes.

Glucose oxidase method (Spinreact, Spain) was used to estimate plasma glucose levels and serum insulin and serum glucagon was done by ELISA technique (DRG international, Inc. USA). Triiodothyronine, thyroxine and thyroid stimulating hormone levels were analyzed by using ELISA kit (CUSABIO BIOTECH CO., LTD). Data was analysed using SPSS version 17. Independent sample's t-test was applied to assess the statistical significance of differences between the control and diabetic groups. p-value $\leq 0.05$ was considered significant. Pearson correlation coefficient was calculated to find correlation between IGR and thyroid hormones.

\section{RESULTS}

All the rats selected for the study were ensured to be normoglycemic and euthyroid by checking their glucose and TSH levels at the beginning of the study. Table-I Presents plasma glucose and serum insulin levels in fasting state. From these values HOMA-IR was calculated at the end of $3^{\text {rd }}$ week of study. Cut off value for plasma glucose is $200 \mathrm{mg} / \mathrm{dl}$ or more and cut off value for HOMA-IR is more than 2. Results in Table-I confirmed the development of T2DM.

In Table-II Comparative analysis of plasma glucose levels, serum insulin levels, HOMA-IR, IGR and thyroid hormones in the terminal samples of the control and diabetic groups has been presented. It shows major difference in plasma glucose levels between the two groups $(p<0.001)$. Levels of the hormone insulin were considerably higher in the diabetic group $(p<0.001)$. In the diabetic group insulin resistance was significantly greater $(p<0.001)$ in comparison to the control group. Serum triiodothyronine (T3) did not change in the diabetic group, however levels of thyroxine (T4) and thyroid stimulating hormone (TSH) were 
found to be considerably higher $(p<0.001)$. Insulin to glucagon ratio (IGR) of the diabetic group was found to be significantly raised $(p<0.001)$.

Pearson's correlation was worked out between insulin to glucagon ratio (IGR) and thyroid profile in both the control group and diabetic group. Results shown in Table-III. Suggest that there is no correlation between IGR and thyroid profile (T3, T4, TSH) in the control group (p-value 0.52, $0.98,0.084$ respectively). Similarly, no correlation was found out between IGR and thyroid profile (T3, T4, TSH) of the diabetic group ( $p$-value 0.71, $0.61,0.66$ respectively).

\section{DISCUSSION}

The interaction of the hormones of pancreas and hormones of thyroid gland in regulating glucose homeostasis in type 2 diabetes was assessed in the current study. An animal model having similar metabolic features as that of type 2 diabetic human was developed. ${ }^{13}$ The development of T2DM was confirmed by the elevated glycemic levels (268.46 $\pm 5.09 \mathrm{mg} / \mathrm{dl})$ and much higher insulin resistance (HOMA-IR) $(8.878 \pm 0.212)$ in the diabetic group.

The examination of blood samples taken at the end of $8^{\text {th }}$ week revealed hyperglycemia $(297.73 \pm 27.05 \mathrm{mg} / \mathrm{dl}), \quad$ hyperinsulinemia (22.29 $\pm 0.49 \mu \mathrm{U} / \mathrm{I})$ and raised HOMA-IR (16.37 \pm 0.41 ) in the diabetic group. In the study conducted on Sprague Dawley rats by Srinivasan et al, diabetes was developed by giving high fat diet and administration of low dose streptozotocin.

\begin{tabular}{|l|c|c|c|}
\hline \multicolumn{1}{|c|}{ Variables } & Control $(\mathbf{n = 3 0})$ & Diabetic $(\mathbf{n}=\mathbf{3 0})$ & P-Value \\
\hline Plasma glucose $(\mathrm{mg} / \mathrm{dl})$ & $93.13 \pm 1.55$ & $268.46 \pm 5.09$ & $<0.001$ \\
\hline Serum insulin $(\mu \mathrm{U} / \mathrm{l})$ & $1.404 \pm 0.04$ & $15.860 \pm 0.338$ & $<0.001$ \\
\hline HOMA-IR & $0.321 \pm 0.009$ & $8.878 \pm 0.212$ & $<0.001$ \\
\hline
\end{tabular}

Table-I. Comparison of fasting plasma glucose, serum insulin and HOMA-IR between diabetic and control groups at the end of 3rd week of study.

All values have been expressed as Mean \pm SEM

\begin{tabular}{|l|c|c|c|}
\hline \multicolumn{1}{|c|}{ Variables } & Control $(\mathbf{n = 3 0})$ & Diabetic $(\mathbf{n = 3 0})$ & P-Value \\
\hline Plasma glucose $(\mathrm{mg} / \mathrm{dl})$ & $95.46 \pm 10.00$ & $297.73 \pm 27.05$ & $<0.001$ \\
\hline Serum insulin $(\mu \mathrm{U} / \mathrm{ml})$ & $1.42 \pm 0.03$ & $22.29 \pm 0.49$ & $<0.001$ \\
\hline $\mathrm{I} / \mathrm{G}$ ratio & $2.3 \pm 0.05$ & $23.9 \pm 0.74$ & $<0.001$ \\
\hline Serum T3 $(\mathrm{ng} / \mathrm{ml})$ & $4.57 \pm 0.30$ & $4.60 \pm 0.12$ & 0.920 \\
\hline Serum T4 $(\mathrm{ng} / \mathrm{ml})$ & $59.9 \pm 2.00$ & $171.73 \pm 2.66$ & $<0.001$ \\
\hline Serum TSH $(\mu \mathrm{U} / \mathrm{ml})$ & $0.354 \pm 0.027$ & $0.924 \pm 0.007$ & $<0.001$ \\
\hline
\end{tabular}

Table-II. Comparison of plasma glucose, serum insulin, HOMA-IR and thyroid profile of control and diabetic groups at the end of the study (08 wks).

All values have been expressed as Mean \pm SEM

\begin{tabular}{|c|c|c|c|}
\hline \multicolumn{1}{|c|}{ Groups } & Thyroid Profile & Pearson's Coefficient & P-value \\
\hline \multirow{3}{*}{ IGR in Control group } & T3 & 0.123 & 0.52 \\
\cline { 2 - 4 } & T4 & 0.004 & 0.98 \\
\hline \multirow{3}{*}{ IGR in Diabetic group } & TSH & 0.321 & 0.084 \\
\cline { 2 - 4 } & T3 & 0.05 & 0.71 \\
\cline { 2 - 4 } & T4 & 0.09 & 0.61 \\
\hline
\end{tabular}

Table-III. Correlation of IGR with thyroid profile.

There was no significant correlation observed between the IGR and thyroid hormones in both control and test groups. 
In this study hyperglycemia was found, which was parallel to the outcome in our study. ${ }^{7}$

Study of thyroid profile of the control and diabetic rats revealed changes in T4 and TSH levels whereas, no change was observed in levels of serum T3 in the diabetic rats. The result of STZ induced diabetes on thyroid profile of male Sprague Dawley rats was studied by Rodger C.D. et al. ${ }^{8}$ Serum T4 levels in their study decreased in diabetic rats when high dose of STZ was administered and also had low levels of insulin. It is established that insulin has a stimulatory effect on growth and multiplication of thyrocytes. Since the level of insulin was low in their study, there was no stimulatory effect on the thyroid cells to produce more thyroxine. $^{9}$

A study conducted in humans analyzed the insulin to glucagon ratio in pathophysiology of various stages of diabetes. It revealed that insulin to glucagon ratio was elevated (12.5) in subjects with uncontrolled type 2 diabetes as compared to the control group (10)..${ }^{10}$ Similarly in present study I/G ratio in diabetic rats was significantly high $(23.9 \pm 0.74)$ due to the significant rise in insulin levels. Serum glucagon levels were also elevated but not as much as insulin. It has been reported that in patients with type 2 diabetes, there occurs loss of inverse relationship between pulsatile insulin and glucagon secretion, which has led to such high IGR. ${ }^{11}$

Correlation between insulin to glucagon ratio (IGR) and thyroid profile of both control and diabetic groups was carried out. Results revealed that there is no correlation between IGR and parameters of thyroid profile in normoglycemic rats. Similarly no correlation was found between IGR and thyroid profile of type 2 diabetic rats. Although various studies have shown that thyroid dysfunction is more common in patients with diabetes than in general population, still no correlation was found between IGR (which is altered in type 2 diabetes) and thyroid profile. ${ }^{9}$

One of the reasons can be the fact that a number of elements effect the secretion of insulin and glucagon. Secondly, the concentrations of insulin and glucagon are extremely variable due to the presence of porto-systemic gradient. ${ }^{12}$ The above mentioned facts do not suggest IGR to be a reliable tool in assessing the relationship of diabetes with thyroid. We have not found studies in literature review which have considered IGR as a tool to assess relationship between diabetes and thyroid dysfunction. It is strongly suggested that underlying cause for the prevalence of thyroid abnormalities in diabetics should be explored further, to have better glycemic control in patients having type 2 diabetes.

\section{CONCLUSION}

Serum glucose, serum insulin and HOMA-IR were raised in the diabetic group. Serum TSH and T4 levels were also increased while no change in serum T3 levels. IGR and thyroid hormones were not correlated in either group.

Copyright@ 08 Nov, 2019.

\section{REFERENCES}

1. Unger RH. Glucoregulatory hormones in health and disease. A teleologic model. Diabetes. 1966; 15:500-6.

2. Unger RH. Glucagon and the insulin: Glucagon ratio in diabetes and other catabolic illnesses. Diabetes. 1971; 20:834-838. doi: 10.2337/diab.20.12.834.

3. Del Prato S, Marchetti P. Beta- and Alpha-Cell dysfunction in type 2 diabetes. Horm Metab Res 2004; 36(11/12): 775-781

4. Wang $C$. The relationship between type 2 diabetes mellitus and related thyroid diseases. J Diabetes Res. 2013; 2013:390534. doi:10.1155/2013/390534

5. Conybeare G, Leslie GB, Angles K, Barrett RJ, Luke JS, Gask DR. An improved simple technique for the collection of blood samples from rats and mice. Lab Anim.1988; 22(2):177-82.

6. Mohan S., Baylink D. J. and Pettis J.L Insulin like growth factor (IGF) binding proteins in serum do they have additional roles besides modulating the endocrine IGF actions. J. Clin. Endocrinol. Metab. 1996; 81(11): 3817-3820.

7. Srinivasan K., Viswanad B., Asrat L., Kaul C.L., Ramarao P. Combination of high-fat diet-fed and low-dose streptozotocin-treated rat: a model for type 2 diabetes and pharmacological screening. Pharmacol. Res; 2005; 52(4): 313-20. 
8. Rodgers C.D., Noble E.G. and Taylor A.W. The effect of STZ induced diabetes on serum triiodothyronine (T3) and thyroxine (T4) levels in the rat: A seven week time course. Diabetes Res.; 1994:26(3): 93-100.

9. Chubb S.A., Davis W.A. and Davis D.M. Interactions among thyroid function, insulin sensitivity and serum lipid concentrations: The Fremantle diabetes study. J. Clin. Endocrinol. Metab; 2005: 90 (9): 5317-20.

10. Menge B.A., Gruber L., Jorgensen S.M., Deacon C.F., Schmidt W.E., Veldhuis J.D., Holst J.J., Meier J.J. Loss of inverse relationship between pulsatile insulin and glucagon secretion in patients with type 2 diabetes. Diabetes; 2011: 60(8): 2160-2168.
11. Wahid M, Naveed A.K. and Hussain I. Insulin and glucagon ratio in the pathophysiology of diabetic ketoacidosis and hyperosmolar hyperglycemic nonketotic diabetes. JCPSP, 2005:16(1): 11-14.

12. Kalra S., Gupta Y. The insulin: Glucagon ratio and the choice of glucose-lowering drugs. Diabetes Their: 2016 7:1-9; DOI 10.1007/s13300-016-0160-4.

13. Srinivasan K, Viswanad B, Asrat L, Kaul CL, Ramarao $P$. Combination of high-fat diet-fed and low-dose streptozotocin-treated rat: A model for type 2 diabetes and pharmacological screening. Pharmacological research. 2005 Oct 1; 52(4):313-20.

\section{Hate is a weak emotion, A sign of failure.}

\section{"Unknown"}

\begin{tabular}{|c|l|l|l|}
\hline \multicolumn{3}{|c}{ AUTHORSHIP AND CONTRIBUTION DECLARATION } \\
\hline Sr. \# & \multicolumn{1}{|c|}{ Author(s) Full Name } & \multicolumn{1}{|c|}{ Contribution to the paper } & Author(s) Signature \\
\hline 1 & Sidra Arshad & $\begin{array}{l}\text { Concept design, Data } \\
\text { collection, critical review. } \\
\text { Concept design, data analysis, } \\
\text { write up. } \\
\text { Concept design, data } \\
\text { collection, critical review. } \\
\text { Conept design, critical review. }\end{array}$ \\
\hline 5 & M. Sajid Mehmood & $\begin{array}{l}\text { Subna Siddique } \\
\text { Concept design, critical review, }\end{array}$ \\
\hline 6 & Hira Ayaz & $\begin{array}{l}\text { Amina Rasul } \\
\text { proof reading. } \\
\text { Concept design, critical review. }\end{array}$ \\
\hline
\end{tabular}

